\title{
Roles of PTEN/PI3K/AKT/GSK3 $\beta$ Pathway in Neuron Signaling Involved in Autism
}

\author{
Akari Minami ${ }^{1}$, Toshiyuki Murai ${ }^{2}$, Atsuko Nakanishi ${ }^{1}$, Yasuko Kitagishi ${ }^{1}$ and Satoru Matsuda ${ }^{1^{*}}$ \\ ${ }^{1}$ Department of Food Science and Nutrition, Nara Women's University, Kita-Uoya Nishimachi, Nara, Japan \\ ${ }^{2}$ Department of Microbiology and Immunology and Department of Genome Biology, Graduate School of Medicine, Osaka University, 2-2 Yamada-oka, Suita, Japan
}

"Corresponding author: Satoru Matsuda, Department of Food Science and Nutrition, Nara Women's University, Kita-Uoya Nishimachi, Nara, Japan, Tel: +81 74220 3451; Fax:+81 74220 3451; E-mail: smatsuda@cc.nara-wu.ac.jp

Rec date: Mar 03, 2015; Acc date: May 04, 2015; Pub date: May 06, 2015

Copyright: ( 2015 Minami A, et al. This is an open-access article distributed under the terms of the Creative Commons Attribution License, which permits unrestricted use, distribution, and reproduction in any medium, provided the original author and source are credited.

\begin{abstract}
Autism spectrum disorder is a set of neurodevelopmental disorders in terms of prevalence, morbidity and impact to the society, which is characterized by intricate behavioral phenotype and deficits in both social and cognitive functions. The molecular pathogenesis of autism spectrum disorder has not been well understood, however, it seems that PI3K, AKT, and its downstream molecules have crucial roles in the molecular pathogenesis of autism spectrum disorder. The PI3K/AKT signaling pathway plays an important role in the regulation of cell proliferation, differentiation, motility, and protein synthesis. Deregulated PI3K/AKT signaling has also been shown to be associated with the autism spectrum disorder. Discovery of molecular biochemical phenotypes would represent a breakthrough in autism research. This study has provided new insight on the mechanism of the disorder and would open up future opportunity for contributions to understand the pathophysiology.
\end{abstract}

Keywords: Autism; ASD; PI3K; AKT; PTEN; GSK3; Signal transduction

\begin{abstract}
Abbreviations:
ASD: Autism Spectrum Disorder; DHA: Docosahexaenonic Acids; EPA: Eicosopentaenoic Acid; GSK3: Glycogen Synthase Kinase 3; 5HT: 5-Hydroxytryptamine, Serotonin; mTOR: Mammalian Target of

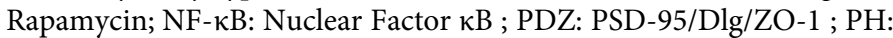
Plekstrin Homology; PIP3: Phosphatidylinositol $(3,4,5)$-Triphosphate; PI3K: Phosphatidylinositol-3 Kinase; PPARy: Peroxisome Proliferator-Activated Receptor $\gamma$; PTEN: Phosphatase and Tensin Homolog on Chromosome 10; PUFAs: Polyunsaturated Fatty Acids; ROS: Reactive Oxygen Species; SSRIs: Selective Serotonin Reuptake Inhibitors; TNF: Tumor Necrosis Factor; TSC1: Tuberous Sclerosis Complex 1; TSC2: Tuberous Sclerosis Complex 2
\end{abstract}

\section{Introduction}

Autism Spectrum Disorder (ASD) is a group of neurodevelopmental disorders defined by an abnormal functioning with the fundamental deficits in social communication and reciprocity, and shows repetitive and categorized patterns of behavior $[1,2]$. ASD is one of the most common behavioral disabilities diagnosed in children, which represent a major public health problem. ASD continues to increase at an upsetting rate [3]. Mixtures of genetic as well as environmental factors are thought to cause the ASD, and more active treatments than those now presented are absolutely required. Several genetic studies have identified a large number of genes which are related to ASD [4]. Many of the genes implicated in ASD encode synaptic proteins [5]. However, most of those gene mutations are rare and may only account for a small part of the cases of ASD. Neuropathological methods applied to ASD brains have revealed several developmental macroscopic and microscopic abnormalities [6], suggesting neuro-inflammation with cytokine production in frontal cortex and cerebellar regions have occurred [6]. In addition, intracellular signal transduction systems including the phosphoinositide 3-kinase/serine-threonine protein kinase AKT (also known as protein kinase $\mathrm{B}$ )/mammalian target of rapamycin (PI3K/AKT/mTOR) pathway in brain have been found to be altered in the ASD patients [7]. Furthermore, gene mutations associated with the regulation of this pathway seem to play a significant role in mediating the behavioral abnormalities characterized in the ASD. Because the pathway also seems to make immune cell activation by regulation of the key inflammatory cytokines [8], changes in the inflammatory signaling might contribute to specific therapeutic effects on ASD treatment. Moreover, recent studies have indicated that several abnormalities of serotonergic system have been described in patients with ASD including abnormal activity of the transporter and reduced serotonin synthesis in brain [9]. Serotonin exerts part of its action by modulating the activity of PI3K/AKT $[10,11]$. Here, we provide an overview of research on the characterization of the regulation of PI3K/AKT signaling (Figure 1) at the viewpoint of pathogenesis in ASD. Understanding those regulations may provide better efficacy of new therapeutic approaches.

\section{Relationship between ASD and Serotonin/GSK3 $\beta$ signaling}

Serotonin (5-HT) is involved in various aspects of normal brain functions including the regulation of mood, appetite and social interactions [12,13]. Accordingly, a neuro-contribution of 5-HT transmission in various human psychiatric conditions and drugs acting on the 5-HT neurotransmission are regularly used for the management of anxiety disorders [14]. Dysregulation of brain 5-HT neurotransmission is thought to surely underlie mental conditions in ASD [9]. Studies have found raised 5-HT levels in the whole blood cells and platelets of ASD patients $[15,16]$. Higher activity of 5-HT transporter has also been implicated in ASD [17]. 5-HT itself or drugs 
acting on the 5-HT neurotransmission control the serine/threonine kinase glycogen synthase kinase 3beta (GSK3 $\beta$ ), a signaling molecule modulated by a lot of psychiatric therapeutic agents $[1,18]$. For example, aripiprazole is an atypical antipsychotic drug accepted for the treatment of psychiatric disorders such as schizophrenia, bipolar disorder, major depressive disorder, and ASD [19]. The drug shows partial agonistic activity at the 5- $\mathrm{HT}(1 \mathrm{~A})$ receptors, and antagonistic activity at the 5-HT(2A) receptors [20]. Furthermore, GSK3 $\beta$ inhibition rescues behavioral abnormalities in the 5-HTdeficient mice [21]. In addition, reduction in brain 5-HT levels is accompanied by activation of the GSK3 $\beta$ [13]. Considerably, inactivation of GSK3 $\beta$ using pharmacological or genetic methods, may improve the aberrant behaviors formed by the 5-HT deficiency. Furthermore, multiple classes of 5-HT drugs, including selective 5-HT reuptake inhibitors (SSRIs), tricyclic antidepressants, monoamine oxidase inhibitors, and atypical antipsychotics, inhibit brain GSK3 $\beta$ signaling [22-24]. GSK3 $\beta$ is inhibited by lithium, which is often used in combination with antidepressants for the management of certain mood disorders [25].

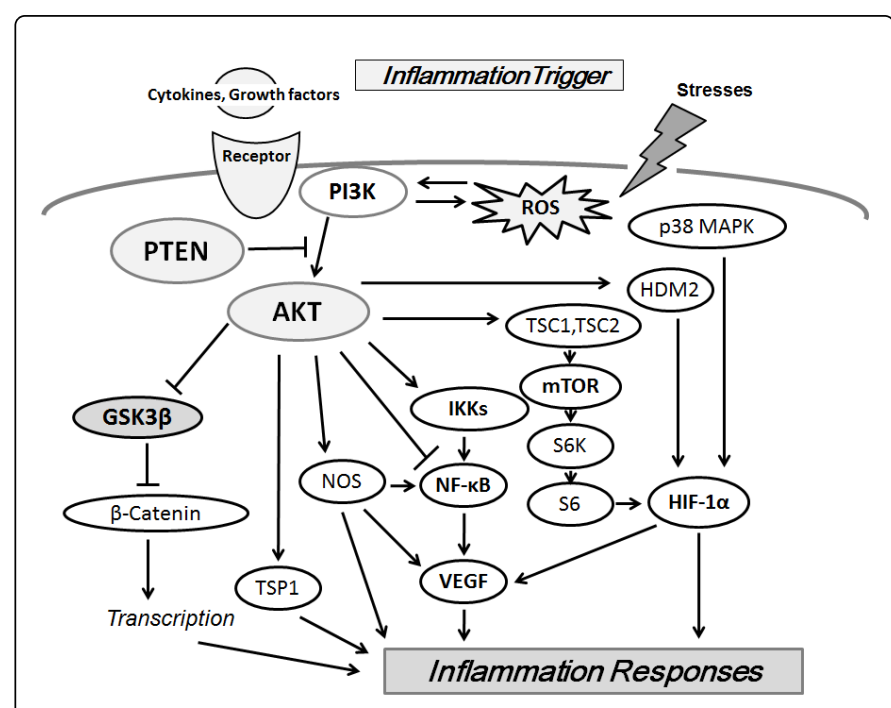

Figure 1: Schematic depiction and overview of a PTEN/PI3K/AKT/ GSK3 $\beta$ signaling in inflammation responses has been shown. Example molecules known to act on the PTEN/PI3K/AKT/GSK3 $\beta$ pathway are also shown. Arrowhead means stimulation whereas hammerhead represents inhibition. Note that some critical pathways have been omitted for clarity.

Unlike many kinases, the GSK3 $\beta$ is a constitutively partial active kinase that is inhibited following the phosphorylation of the Ser-9 residue located in its amino-terminal domain [26] (Figure 2). In brain, stimulation of 5-HT (1A) receptors augments phosphorylation of the Ser-9 residue, thus leading to inhibition of the GSK3 $\beta$ [27]. In contrast, 5-HT (2A) receptor signaling reduces GSK3 $\beta$ phosphorylation thus leading to kinase activation [28]. Inhibition of this kinase prevents the appearance of behavioral changes brought by 5-HT-deficiency in mice experiments [29]. Accordingly, targeting GSK3 $\beta$ signaling may give therapeutic advantages for the controlling of certain 5-HT-related psychiatric conditions. In consistent, inhibitory serine- 9 phosphorylation of GSK3 $\beta$ is also essential for the action of lithium [30]. Either directly or indirectory, mood stabilizers lithium and valproic acid trigger an inhibition of GSK3 $\beta[31,32]$. In addition, various drugs acting on 5-HT neurotransmission are capable of inhibiting GSK3 $\beta$ activity by increasing the inhibitory phosphorylation of the amino-terminal domain serine- 9 residue [33,34]. Although the GSK3 $\beta$ was first identified as an enzyme phosphorylating glycogen synthase, it has been found to phosphorylate a lot of intracellular substrates [35]. Through the phosphorylation, GSK3 $\beta$ regulates many important cellular processes, including development, cell structure, microtubule dynamics, gene expression, and cell survival [35]. GSK3 $\beta$ is a ubiquitous serine/ threonine kinase which is usually referred to as GSK3 isoforms, GSK3 $\alpha$ and GSK3 $\beta$ [36]. These two iso-enzymes are the product of different genes termed GSK3 $\alpha$ and GSK3 $\beta$. The development of GSK3 isoform-specific inhibitors seems to be necessary for the treatment with the GSK3-mediated pathology [37]. The regulation of GSK3 by $5 \mathrm{HT}(1 \mathrm{~A})$ receptors appears to involve an activation of phosphoinositide 3-kinase (PI3K) which in turn activates the serine/ threonine kinase AKT, then phosphorylates the inhibitory serine 9 residue of GSK3 $\beta$ [27]. In addition to its regulation by $5-\mathrm{HT}$, brain GSK3 $\beta$ is also inactivated by several neurotrophic factors, such as the brain-derived neurotrophic factor and its receptor TrkB through PI3K-mediated signaling [38,39]. Drugs that influence the 5-HT system can also regulate GSK3 $\beta$ in certain brain areas [21]. Accordingly, systemic inhibition of GSK3 $\beta$ has been shown to have effects similar to those of mood stabilizers, antipsychotics or antidepressants. Numerous classes of pharmacological compounds may differentially modulate GSK3 $\beta$ activity in the brain neuronal networks.

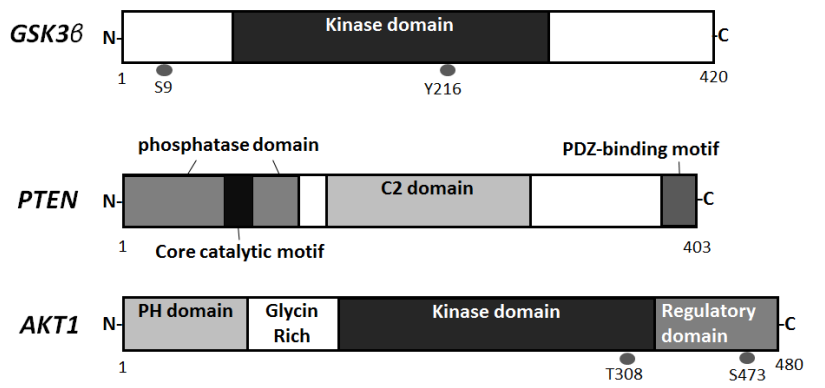

Figure 2: Schematic protein structures of human GSK3 $\beta$, PTEN and AKT1. The functionally important phosphorylation sites are also shown. Note that the sizes of protein are modified for clarity. $\mathrm{PH}$ domain $=$ pleckstrin homology domain; $\mathrm{C} 2$ domain $=$ a protein structural domain involved in targeting proteins to cell membranes; $\mathrm{PDZ}=\mathrm{a}$ common structural domain in signaling proteins (PSD9, $\mathrm{Dlg}, \mathrm{ZO}-$, etc)

\section{Relationship between ASD and PTEN}

Increasing form of evidence suggests dysregulated PI3K activity and downstream signaling as a significant contributor and potential therapeutic targets for mental disorders [7,40]. Signaling through the $\mathrm{PI} 3 \mathrm{~K}$ has various essential roles such as cell growth, migration, differentiation and cell survival [41]. The PI3K activity is also known as a crucial regulator of neuronal function [42]. PI3K signaling transduces various signals from cell surface receptors to the AKT/ mTOR pathway, and is crucial for synapse and dendritic spine development [42], and for enduring forms of synaptic plasticity underlying memory and learning [43]. Accordingly, alteration in the $\mathrm{PI} 3 \mathrm{~K} / \mathrm{AKT} / \mathrm{mTOR}$ pathway results in many behavioral abnormalities 
and is also expected to play a significant role in ASD pathogenesis. Actually, alteration of the downstream mTOR signaling pathway has been shown to be involved in $14 \%$ of ASD individuals [44]. Phosphatase and tensin homolog on chromosome 10 (PTEN) has lipid phosphatase activity against the 3'phosphate of phosphatidylinositol , 5 trisphosphate, which negatively regulates the activity of PI3K/AKT pathway [45]. In other words, PI3K catalyzes the reverse of PTEN reaction resulting in AKT activation. Then, AKT phosphorylates a diverse set of substrates including GSK3 $\beta$ [46]. 5-HT promotes interactions with a scaffolding and regulatory molecule, which results in the activation of PI3K/AKT [47]. Therefore, the PTEN may be a significant regulator of this pathway in mediating the ASD phenotype. In a clinical cohort of pediatric patients with ASD, there is a prevalence rate of about $8 \%$ with mutations in PTEN gene [48]. Developmental delay and/or mental retardation have a higher prevalence rate with mutations in PTEN [49]. Functional absence of PTEN results in an enlarged hippocampus with increased size of brain dendrite [50]. In contrast, overexpression of PTEN has been shown to have inhibitory effects on 5-HT signaling via the decreased AKT activity [51]. It has been shown that PTEN is a tumor suppressor gene mutated in a lot of human cancers [52]. Individuals with germline PTEN mutations are susceptible to tumors but also display brain disorders together with macrocephaly, seizure, and mental retardation [53]. As mentioned above, PTEN mutations have also been reported in ASD individuals [54]. Downstream of the PI3K/AKT pathway, some components of the mTOR signaling are present in synapses and mediate synaptic plasticity in specific neuronal residents [55]. So, abnormal activation of the PI3K/AKT pathway could underlie behavioral abnormalities reminiscent certain features of human ASD. However, a causal link between PTEN and ASD remains unclear.

\section{Diets may contribute to the improvement of ASD- therapy via the modulation of PTEN/AKT and GSK3 $\beta$ signaling}

Fish oil administration amends cognitive deficit, increases AKT phosphorylation, decreases GSK3 $\beta$ phosphorylation, and decreases pro-apoptotic molecule-expression, suggesting a potential role for fish oil as a protection of neurons [56]. In particular, omega-3 (n-3) longchain polyunsaturated fatty acids (PUFAs) in the fish oil have become a focus of interest. Docosahexaenonic acids (DHA) are essential for brain development [57]. Fish oil administration also improves cognitive deficit by the increasing AKT phosphorylation [58]. Accordingly, neuroprotecton could be performed by certain diets involved in PI3K/AKT pathway. A variety of signals from food nutrients leads to the PI3K/AKT and GSK3 $\beta$ pathway activation and/or inhibition (Figure 3). For example, phosphorylation of Ser9 in GSK3 $\beta$ is significantly increased in green tea polyphenols-treated HepG2 cells [59]. In mice experiments, resveratrol may provide neuroprotection via the increases in the GSK3 $\beta$ phosphorylation [60]. Dietary depletion of tryptophan, which is the precursor of 5-HT, has been shown to exacerbate the repetitive behavior in ASD patients [61]. In consistent, tryptophan-restricted animals display a reduced activity of phosphorylated AKT [62]. It is also suggested that the neuroprotection of curcumin might be mediated via PI3K/AKT signaling pathway [63]. Curcumin, a component in the widely used culinary spice turmeric, could improve the plasticity and structure of synapse, and could improve memory capacities [64]. Furthermore, an apparent anxiolytic effect of curcumin has been shown in lead induced animal anxiety-model, possibly resulted from modulation of neuronal 5-HT neurotransmission [65]. Kaempferol is a flavonol present in various plants such as grapefruit and some edible berries, which induces the activation of PI3K/AKT signaling [66]. On the contrary, the biological activity of the isothiocyanates, rich in some vegetables such as broccoli, has been shown to suppress AKT phosphorylation [67]. However, despite these experimental observations, the exact mechanisms for these food ingredients remain elusive for the clinical uses. Additionally, it seems essential to exploit the potential profits of optimal treatment and/or combination with these PI3K/AKT modulators.

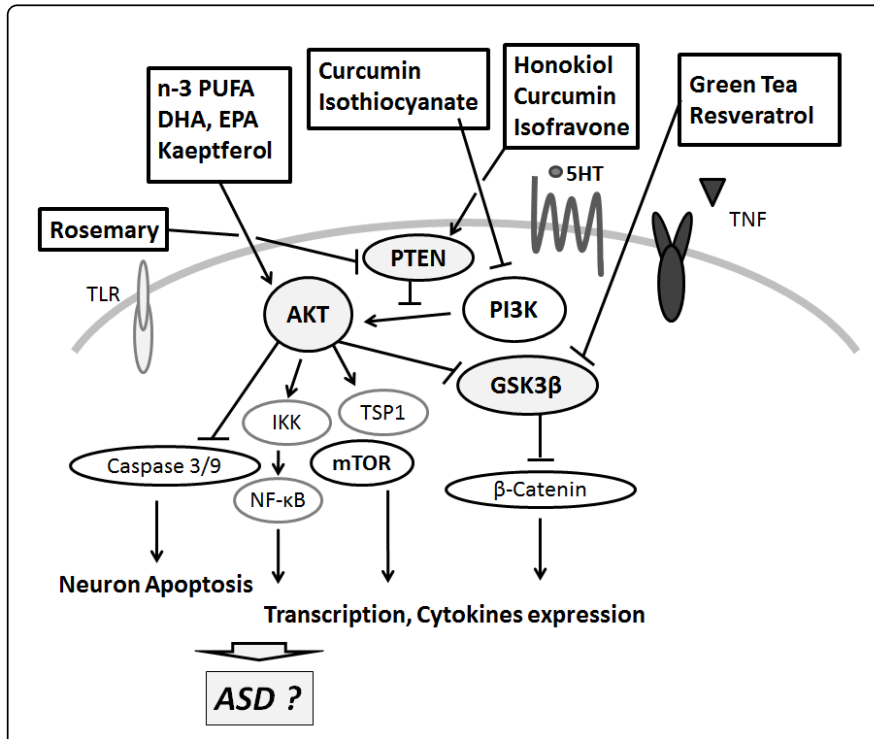

Figure 3: Several dietary modulators linked to the PTEN/ PI3K/AKT/GSK3 $\beta$ pathway are demonstrated, whose potential molecular targets may be based on the predominant sites. Arrowhead means stimulation whereas hammerhead represents inhibition, suggesting implication of PTEN/PI3K/AKT/GSK3 $\beta$ modulators for the therapy of ASD via the neuronal cells protection. Note that some critical events have been omitted for clarity.

Therapeutic and/or dietary interventions to respond the reduction of PTEN expression could contribute to the prevention of the anxiety diseases and/or could decline the rate of its development. Honokiol, a compound in traditional eastern herbal medicines, can chemically diminish the PI3K/AKT signaling by up-regulation of PTEN expression [68]. However, PTEN indirectly promotes 5-HT synthesis and secretion via inhibiting the signaling $[69,70]$. In addition, there is a crosstalk between PTEN and 5-HT receptor [70]. It has been shown that DHA and eicosopentaenoic acid (EPA) increase the level of PTEN in breast cancer cells [71]. Since DHA and EPA are ligands of PPAR $\gamma$, both of the n-3 PUFAs exert anti-proliferative effects by inducing PTEN expression via the activation of the PPAR $\gamma$ [72]. In this meaning, the most attractive target with regard to PTEN transcription seems to be PPAR $\gamma$ [73]. Both genistein and quercetin, daidzein also have an effect on the PPAR $\gamma$ activation which has been shown to upregulate PTEN expression, then, suppresses the PI3K/AKT pathway [74]. Therefore, dietary exposure to the soy isoflavones at physiologically relevant concentrations induces PTEN expression [75]. A high-fat diet raises circulating fatty acids, which considerably modifies PTEN expression [76]. Remarkably, some of rosemary extract represses PTEN expression in K562 culture cells [77]. 
Additionally, dietary consumption of the indole-3-carbinol upregulates PTEN in the animal model [78]. In the future, these findings might be interpreted into new dietary managements for the treatment of ASD via the regulation of AKT/PTEN signaling pathway.

\section{Perspective}

Overall, the effect of depletion in brain GSK3 $\beta$ activity is a reduction in anxiety that is combined with an increase in the beginning of social interaction. As mentioned above, previous studies have shown that GSK3 $\beta$ would be commonly activated by 5 -HT ( $2 \mathrm{~A}$ ) receptors and inhibited by $5-\mathrm{HT}(1 \mathrm{~A})$ receptors $[27,28]$. Changes in the regulation of GSK3 $\beta$ activity have been associated with the actions of several psychoactive drugs, including those affecting 5-HT functions in the treatment of mood disorders. A better understanding of the functions of GSK3 $\beta$ in different brain areas may be the key to unravel the mechanisms by which it contributes to the regulation of ASD treatment. Investigations of the function and mechanisms of GSK3 $\beta$ mediated signaling in 5-HT synaptic transmission should offer research possibilities to understand and potentially manage human disorders. PTEN/PI3K/AKT/GSK3 $\beta$ pathway seems to be critical for maintenance in brain neurons. As enzymes involved in neuronal cell survival and neuroplasticity is particularly relevant to the function of neurotrophic factor, regulation of PTEN/PI3K/AKT/GSK3 $\beta$ may provide an important signaling for the neuroprotection in ASD. Among different signaling molecules that can be regulated by $5-\mathrm{HT}$, several lines of evidence support a role for this signaling networks underlying the development and treatment of mental illnesses. Accordingly, one treatment model is based on the regulation in the ASD children. Given the complexity of the signaling pathways that can regulate brain activity, it is probable that this pathway might contribute to the therapeutic effect of dietary treatment on ASD. The benefits from dietary supplementation may extend to a wider population.

\section{Acknowledgments}

This work was supported by JSPS KAKENHI Grant Number 25560050, 26-1203, 24240098.

\section{References}

1. Gadad BS, Hewitson L, Young KA, German DC (2013) Neuropathology and animal models of autism: genetic and environmental factors. Autism Res Treat 2013: 731935.

2. Elamin NE, Al-Ayadhi LY (2014) Brain autoantibodies in autism spectrum disorder. Biomark Med 8: 345-352.

3. Keyes KM, Susser E, Cheslack-Postava K, Fountain C, Liu K, et al. (2012) Cohort effects explain the increase in autism diagnosis among children born from 1992 to 2003 in California. Int J Epidemiol 41: 495-503.

4. Abrahams BS, Geschwind DH (2008) Advances in autism genetics: on the threshold of a new neurobiology. Nat Rev Genet 9: 341-355.

5. Delorme R, Ey E, Toro R, Leboyer M, Gillberg C, et al. (2013) Progress toward treatments for synaptic defects in autism. Nat Med 19: 685-694.

6. Courchesne E, Townsend J, Saitoh O (1994) The brain in infantile autism: posterior fossa structures are abnormal. Neurology 44: 214-223.

7. Chen J, Alberts I, Li X (2014) Dysregulation of the IGF-I/PI3K/AKT/ mTOR signaling pathway in autism spectrum disorders. Int $\mathrm{J}$ Dev Neurosci 35: 35-41.

8. Ding J, Feng T, Ning Y, Li W, Wu Q, et al. (2015) $\hat{\mathrm{I}}^{2}$-Glucan enhances cytotoxic $\mathrm{T}$ lymphocyte responses by activation of human monocytederived dendritic cells via the PI3K/AKT pathway. Hum Immunol 76: 146-154.
9. Ciranna L, Catania MV (2014) 5-HT7 receptors as modulators of neuronal excitability, synaptic transmission and plasticity: physiological role and possible implications in autism spectrum disorders. Front Cell Neurosci 8: 250.

10. Beaulieu JM, Gainetdinov RR, Caron MG (2009) Akt/GSK3 signaling in the action of psychotropic drugs. Annu Rev Pharmacol Toxicol 49: 327-347.

11. Musazzi L, Seguini M, Mallei A, Treccani G, Pelizzari M, et al. (2014) Time-dependent activation of MAPK/Erk1/2 and Akt/GSK3 cascades: modulation by agomelatine. BMC Neurosci 15: 119 .

12. Taheri-Kafrani A, Choiset Y, Faizullin DA, Zuev YF, Bezuglov VV, et al. (2011) Interactions of $\hat{I}^{2}$-lactoglobulin with serotonin and arachidonyl serotonin. Biopolymers 95: 871-880.

13. Manuel-Apolinar L, Rocha L, Damasio L, Tesoro-Cruz E, Zarate A (2014) Role of prenatal undernutrition in the expression of serotonin, dopamine and leptin receptors in adult mice: implications of food intake. Mol Med Rep 9: 407-412.

14. Beaulieu JM, Zhang X, Rodriguiz RM, Sotnikova TD, Cools MJ, et al. (2008) Role of GSK3 beta in behavioral abnormalities induced by serotonin deficiency. Proc Natl Acad Sci U S A 105: 1333-1338.

15. Spivak B, Golubchik P, Mozes T, Vered Y, Nechmad A, et al. (2004) Low platelet-poor plasma levels of serotonin in adult autistic patients. Neuropsychobiology 50: 157-160.

16. Cross S, Kim SJ, Weiss LA, Delahanty RJ, Sutcliffe JS, et al. (2008) Molecular genetics of the platelet serotonin system in first-degree relatives of patients with autism. Neuropsychopharmacology 33: 353-360.

17. Iwata K, Matsuzaki H, Tachibana T, Ohno K, Yoshimura S, et al. (2014) N-ethylmaleimide-sensitive factor interacts with the serotonin transporter and modulates its trafficking: implications for pathophysiology in autism. Mol Autism 5: 33.

18. Rybakowski JK (2013) Genetic influences on response to mood stabilizers in bipolar disorder: current status of knowledge. CNS Drugs 27: 165-173.

19. Wink LK, Early M, Schaefer T, Pottenger A, Horn P, et al. (2014) Body mass index change in autism spectrum disorders: comparison of treatment with risperidone and aripiprazole. J Child Adolesc Psychopharmacol 24: 78-82.

20. Zajdel P, Marciniec K, Maslankiewicz A, Grychowska K, Satala G, et al. (2013) Antidepressant and antipsychotic activity of new quinoline- and isoquinoline-sulfonamide analogs of aripiprazole targeting serotonin 5HT1A/5-HT2A/5-HT7 and dopamine D2/D3 receptors. Eur J Med Chem 60: 42-50.

21. Latapy C, Rioux V, Guitton MJ, Beaulieu JM (2012) Selective deletion of forebrain glycogen synthase kinase $3 ß$ reveals a central role in serotoninsensitive anxiety and social behaviour. Philos Trans R Soc Lond B Biol Sci 367: 2460-2474.

22. Tseng YL, Chiang ML, Lane HY, Su KP, Lai YC (2013) Selective serotonin reuptake inhibitors reduce P2Y12 receptor-mediated amplification of platelet aggregation. Thromb Res 131: 325-332.

23. Bauer M, Adli M, Ricken R, Severus E, Pilhatsch M (2014) Role of lithium augmentation in the management of major depressive disorder. CNS Drugs 28: 331-342.

24. Kashyap MP, Singh AK, Kumar V, Yadav DK, Khan F, et al. (2013) Pkb/ Akt1 mediates Wnt/GSK3ß/ß-catenin signaling-induced apoptosis in human cord blood stem cells exposed to organophosphate pesticide monocrotophos. Stem Cells Dev 22: 224-238.

25. Xu W, Ge Y, Liu Z, Gong R (2015) Glycogen synthase kinase $3 \hat{\mathrm{I}}^{2}$ orchestrates microtubule remodeling in compensatory glomerular adaptation to podocyte depletion. J Biol Chem 290: 1348-1363.

26. Lee YI, Seo M, Kim Y, Kim SY, Kang UG, et al. (2005) Membrane depolarization induces the undulating phosphorylation/ dephosphorylation of glycogen synthase kinase 3beta, and this dephosphorylation involves protein phosphatases 2A and 2B in SH-SY5Y human neuroblastoma cells. J Biol Chem 280: 22044-22052.

27. Polter AM, Yang S, Jope RS, Li X (2012) Functional significance of glycogen synthase kinase-3 regulation by serotonin. Cell Signal 24: 265-271. 
28. Bharti S, Singh R, Chauhan SS, Hussain T, Al-Attas OS, et al. (2012) Phosphorylation of Akt/GSK-3//eNOS amplifies 5-HT2B receptor blockade mediated anti-hypertrophic effect in rats. FEBS Lett 586: 180-185.

29. Waider J, Proft F, Langlhofer G, Asan E, Lesch KP, et al. (2013) GABA concentration and GABAergic neuron populations in limbic areas are differentially altered by brain serotonin deficiency in Tph2 knockout mice. Histochem Cell Biol 139: 267-281.

30. Kirshenboim N, Plotkin B, Shlomo SB, Kaidanovich-Beilin O, EldarFinkelman H (2004) Lithium-mediated phosphorylation of glycogen synthase kinase-3beta involves PI3 kinase-dependent activation of protein kinase C-alpha. J Mol Neurosci 24: 237-245.

31. De Sarno P, Li X, Jope RS (2002) Regulation of Akt and glycogen synthase kinase- 3 beta phosphorylation by sodium valproate and lithium. Neuropharmacology 43: 1158-1164.

32. Large CH, Di Daniel E, Li X, George MS (2009) Neural network dysfunction in bipolar depression: clues from the efficacy of lamotrigine. Biochem Soc Trans 37: 1080-1084.

33. Bartl J, Meyer A, Brendler S, Riederer P, Grünblatt E (2013) Different effects of soluble and aggregated amyloid $\hat{I}^{2} 42$ on gene/protein expression and enzyme activity involved in insulin and APP pathways. J Neural Transm 120: 113-120.

34. Warden SJ, Hassett SM, Bond JL, Rydberg J, Grogg JD, et al. (2010) Psychotropic drugs have contrasting skeletal effects that are independent of their effects on physical activity levels. Bone 46: 985-992.

35. Lin YT, Cheng JT, Liang LC, Ko CY, Lo YK, et al. (2007) The binding and phosphorylation of Thr231 is critical for Tau's hyperphosphorylation and functional regulation by glycogen synthase kinase 3beta. J Neurochem 103: 802-813.

36. Ma T (2014) GSK3 in Alzheimer's disease: mind the isoforms. J Alzheimers Dis 39: 707-710.

37. Liang MH, Chuang DM (2007) Regulation and function of glycogen synthase kinase-3 isoforms in neuronal survival. J Biol Chem 282: 3904-3917.

38. Li Z, Tan F, Thiele CJ (2007) Inactivation of glycogen synthase kinase-3beta contributes to brain-derived neutrophic factor/TrkBinduced resistance to chemotherapy in neuroblastoma cells. Mol Cancer Ther 6: 3113-3121.

39. Jain V, Baitharu I, Prasad D, Ilavazhagan G (2013) Enriched environment prevents hypobaric hypoxia induced memory impairment and neurodegeneration: role of $\mathrm{BDNF} / \mathrm{PI} 3 \mathrm{~K} / \mathrm{GSK} 3 \hat{\mathrm{I}}^{2}$ pathway coupled with CREB activation. PLoS One 8: e62235.

40. Clipperton-Allen AE, Page DT (2014) Pten haploinsufficient mice show broad brain overgrowth but selective impairments in autism-relevant behavioral tests. Hum Mol Genet 23: 3490-3505.

41. Chen J, Crawford R, Chen C, Xiao Y (2013) The key regulatory roles of the PI3K/Akt signaling pathway in the functionalities of mesenchymal stem cells and applications in tissue regeneration. Tissue Eng Part B Rev 19: 516-528.

42. Lee CC, Huang CC, Hsu KS (2011) Insulin promotes dendritic spine and synapse formation by the PI3K/Akt/mTOR and Rac1 signaling pathways. Neuropharmacology 61: 867-879.

43. Hoeffer CA, Klann E (2010) mTOR signaling: at the crossroads of plasticity, memory and disease. Trends Neurosci 33: 67-75.

44. de Vries AL, Noens IL, Cohen-Kettenis PT, van Berckelaer-Onnes IA, Doreleijers TA (2010) Autism spectrum disorders in gender dysphoric children and adolescents. J Autism Dev Disord 40: 930-936.

45. De Melo J, He L, Tang D (2014) The protein-protein interactionmediated inactivation of PTEN. Curr Mol Med 14: 22-33.

46. Zhao H, Sapolsky RM, Steinberg GK (2006) Phosphoinositide-3kinase/akt survival signal pathways are implicated in neuronal survival after stroke. Mol Neurobiol 34: 249-270.

47. de Bartolomeis A, Buonaguro EF, Iasevoli F (2013) Serotonin-glutamate and serotonin-dopamine reciprocal interactions as putative molecular targets for novel antipsychotic treatments: from receptor heterodimers to postsynaptic scaffolding and effector proteins. Psychopharmacology (Berl) 225: 1-19.

48. McBride KL, Varga EA, Pastore MT, Prior TW, Manickam K, et al. (2010) Confirmation study of PTEN mutations among individuals with autism or developmental delays/mental retardation and macrocephaly. Autism Res 3: 137-141.

49. Varga EA, Pastore M, Prior T, Herman GE, McBride KL (2009) The prevalence of PTEN mutations in a clinical pediatric cohort with autism spectrum disorders, developmental delay, and macrocephaly. Genet Med 11: 111-117.

50. Schumann CM, Hamstra J, Goodlin-Jones BL, Lotspeich LJ, Kwon H, et al. (2004) The amygdala is enlarged in children but not adolescents with autism; the hippocampus is enlarged at all ages. J Neurosci 24: 6392-6401.

51. Silva SR, Zaytseva YY, Jackson LN, Lee EY, Weiss HL, et al. (2011) The effect of PTEN on serotonin synthesis and secretion from the carcinoid cell line BON. Anticancer Res 31: 1153-1160.

52. Nakanishi A, Kitagishi Y, Ogura Y, Matsuda S (2014) The tumor suppressor PTEN interacts with p53 in hereditary cancer (Review). Int J Oncol 44: 1813-1819.

53. Garcia-Junco-Clemente P, Golshani P (2014) PTEN: A master regulator of neuronal structure, function, and plasticity. Commun Integr Biol 7: e28358.

54. Busa T, Milh M, Degardin N, Girard N, Sigaudy S, et al. (2015) Clinical presentation of PTEN mutations in childhood in the absence of family history of Cowden syndrome. Eur J Paediatr Neurol 19: 188-192.

55. Christie KJ, Webber CA, Martinez JA, Singh B, Zochodne DW (2010) PTEN inhibition to facilitate intrinsic regenerative outgrowth of adult peripheral axons. J Neurosci 30: 9306-9315.

56. Sun LJ, Hou XH, Xue SH, Yan F, Dai YJ, et al. (2014) Fish oil modulates glycogen synthase kinase-3 signaling pathway in diabetes-induced hippocampal neurons apoptosis. Brain Res 1574: 37-49.

57. Janssen CI, Kiliaan AJ (2014) Long-chain polyunsaturated fatty acids (LCPUFA) from genesis to senescence: the influence of LCPUFA on neural development, aging, and neurodegeneration. Prog Lipid Res 53: $1-17$.

58. Jia D, Heng LJ, Yang RH, Gao GD (2014) Fish oil improves learning impairments of diabetic rats by blocking PI3K/AKT/nuclear factor- $\hat{I}^{\circ} \mathrm{B}-$ mediated inflammatory pathways. Neuroscience 258: 228-237.

59. Kim JJ, Tan Y, Xiao L, Sun YL, Qu X (2013) Green tea polyphenol epigallocatechin-3-gallate enhance glycogen synthesis and inhibit lipogenesis in hepatocytes. Biomed Res Int 2013: 920128.

60. Varamini B, Sikalidis AK, Bradford KL (2014) Resveratrol increases cerebral glycogen synthase kinase phosphorylation as well as protein levels of drebrin and transthyretin in mice: an exploratory study. Int J Food Sci Nutr 65: 89-96.

61. Boccuto L, Chen CF, Pittman AR, Skinner CD, McCartney HJ, et al. (2013) Decreased tryptophan metabolism in patients with autism spectrum disorders. Mol Autism 4: 16.

62. Penedo LA, Oliveira-Silva P, Gonzalez EM, Maciel R, Jurgilas PB, et al. (2009) Nutritional tryptophan restriction impairs plasticity of retinotectal axons during the critical period. Exp Neurol 217: 108-115.

63. Wang R, Li YH, Xu Y, Li YB, Wu HL, et al. (2010) Curcumin produces neuroprotective effects via activating brain-derived neurotrophic factor/ TrkB-dependent MAPK and PI-3K cascades in rodent cortical neurons. Prog Neuropsychopharmacol Biol Psychiatry 34: 147-153.

64. Zhang L, Luo J, Zhang M, Yao W, Ma X, et al. (2014) Effects of curcumin on chronic, unpredictable, mild, stress-induced depressive-like behaviour and structural plasticity in the lateral amygdala of rats. Int J Neuropsychopharmacol 17: 793-806.

65. Benammi H, El Hiba O, Romane A, Gamrani H (2014) A blunted anxiolytic like effect of curcumin against acute lead induced anxiety in rat: involvement of serotonin. Acta Histochem 116: 920-925.

66. Marfe G, Tafani M, Indelicato $M$, Sinibaldi-Salimei $P$, Reali V, et al. (2009) Kaempferol induces apoptosis in two different cell lines via Akt 
Citation: $\quad$ Minami A, Murai T, Nakanishi A, Kitagishi Y, Matsuda S (2015) Roles of PTEN/PI3K/AKT/GSK3 $\beta$ Pathway in Neuron Signaling Involved in Autism. Brain Disord Ther 4: 165. doi:10.4172/2168-975X.1000165

Page 6 of 6

inactivation, Bax and SIRT3 activation, and mitochondrial dysfunction. J Cell Biochem 106: 643-650.

67. Boreddy SR, Pramanik KC, Srivastava SK (2011) Pancreatic tumor suppression by benzyl isothiocyanate is associated with inhibition of PI3K/AKT/FOXO pathway. Clin Cancer Res 17: 1784-1795.

68. Liu H, Zang C, Emde A, Planas-Silva MD, Rosche M, et al. (2008) Antitumor effect of honokiol alone and in combination with other anticancer agents in breast cancer. Eur J Pharmacol 591: 43-51.

69. Anastasio NC, Gilbertson SR, Bubar MJ, Agarkov A, Stutz SJ, et al. (2013) Peptide inhibitors disrupt the serotonin 5-HT2C receptor interaction with phosphatase and tensin homolog to allosterically modulate cellular signaling and behavior. J Neurosci 33: 1615-1630.

70. Cai J, Yi Z, Lu W, Fang Y, Zhang C (2013) Crosstalk between 5-HT2cR and PTEN signaling pathway in atypical antipsychotic-induced metabolic syndrome and cognitive dysfunction. Med Hypotheses 80: 486-489.

71. Ghosh-Choudhury T, Mandal CC, Woodruff K, St Clair P, Fernandes G, et al. (2009) Fish oil targets PTEN to regulate NFkappaB for downregulation of anti-apoptotic genes in breast tumor growth. Breast Cancer Res Treat 118: 213-228.

72. Rovito D, Giordano C, Vizza D, Plastina P, Barone I, et al. (2013) Omega-3 PUFA ethanolamides DHEA and EPEA induce autophagy through PPAR $\gamma$ activation in MCF-7 breast cancer cells. J Cell Physiol 228: 1314-1322.

73. Montales MT, Rahal OM, Nakatani H, Matsuda T, Simmen RC (2013) Repression of mammary adipogenesis by genistein limits mammosphere formation of human MCF-7 cells. J Endocrinol 218: 135-149.

74. Wang L, Waltenberger B, Pferschy-Wenzig EM, Blunder M, Liu X, et al. (2014) Natural product agonists of peroxisome proliferator-activated receptor gamma (PPAR?): a review. Biochem Pharmacol

75. Dave B, Eason RR, Till SR, Geng Y, Velarde MC, et al. (2005) The soy isoflavone genistein promotes apoptosis in mammary epithelial cells by inducing the tumor suppressor PTEN. Carcinogenesis 26: 1793-1803.

76. La Merrill M, Gordon RR, Hunter KW, Threadgill DW, Pomp D (2010) Dietary fat alters pulmonary metastasis of mammary cancers through cancer autonomous and non-autonomous changes in gene expression. Clin Exp Metastasis 27: 107-116.

77. Yoshida H, Okumura N, Kitagishi Y, Nishimura Y, Matsuda S (2011) Ethanol extract of Rosemary repressed PTEN expression in K562 culture cells. Int J appl Boil pharm Technol 2: 316-322.

78. Qi M, Anderson AE, Chen DZ, Sun S, Auborn KJ (2005) Indole-3carbinol prevents PTEN loss in cervical cancer in vivo. Mol Med 11: 59-63. 